\title{
Suppressive Effect of a Carbohydrate Fraction from Eclipta prostrata on the Apoptosis of the Mouse Splenocytes in Culture
}

\author{
Eun Kyong BAE${ }^{1}$, Nari KıM${ }^{1}$, Mi Jung Yun ${ }^{1}$, Hyongchol Kyungjoon Youn², \\ Kang Ro LeE ${ }^{3}$, and Hyun Joo Youn ${ }^{1^{*}}$ \\ ${ }^{1}$ School of Biological Sciences and Bio-health Products Research Center, Inje University, Gimhae, 621-749, Republic of Korea \\ ${ }^{2}$ School of Biological Sciences, Seoul National University, Seoul, 151-742, Republic of Korea \\ ${ }^{3}$ Natural Products Laboratory, College of Pharmacy, Sungkyunkwan University, Suwon 440-746, Republic of Korea
}

(Received September 16, 2008; Revised October 22, 2008; Accepted October 23, 2008)

\begin{abstract}
Eclipta prostrata grows abundantly in the tropical and the sub-tropical parts of the world including most part of the Korean Peninsula. The plant has been traditionally used for the treatment of a number of inflammatory diseases including hepatitis and enteritis but the nature of its immuno-modulating activity needs more studies. In this study, water-soluble sugar-containing fractions were purified from the herb and their effects on the culture of mouse splenocytes were examined. One of the fractions significantly suppressed apoptosis of the splenocytes in culture, which involves the gene expression regulation of a number of cytokines and cytokine receptors including MIP1- $\beta$. This study could explain an immunological activity of Eclipta prostrata and would lead to identify an immuno-active compound from the plant.
\end{abstract}

Keywords: Apoptosis, Eclipta, Splenocytes, Carbohydrates, MIP1- $\beta$

\section{INTRODUCTION}

Eclipta prostrata is an annual tropical and subtropical plant and also grows abundantly throughout the Korean Peninsula. It is regarded as an edible plant in Korea and also a traditional medicinal herb used for the treatment of a number of inflammatory diseases including hepatitis and enteritis (Han et al., 1998). It has also been reported that the herb could be applied for the allergic conditions like cough and asthma (Kobari et al., 2004). An alcoholic extract of the plant showed protective activity against the myotoxic and hemorrhagic effects of a snake venom (Mores et al., 1998) and also revealed lipid-lowering activity (Kumari et al., 2006). In Thailand, Eclipta prostrata has been prescribed for AIDS patients and a number of compounds with anti-HIV activity were purified from the plant (Tewtrakul et al., 2007). Though many of these findings indicate that the plant may present immuno-modulating activity, its nature requires more studies in cellular and molecular levels.

Programmed cell death or apoptosis is an important

\footnotetext{
${ }^{*}$ Corresponding author

Tel: +82-55-320-3265 Fax: +82-55-336-7706

E-mail: mbhjyoun@inje.ac.kr
}

process in the homeostatic regulation of many cell types of the immune system and also plays a role in the regulation of immune responses as well as in the pathogenesis of a variety of immune disorders (Lindsten et al., 2000). Apoptosis is a tightly regulated process and can be induced by a diverse range of stimuli from either inside or outside of a cell (Ishizaki et al., 1995; Luo et al., 1998). Extracellular apoptotic signals can be originated from death receptor bindings, which may induce or suppress apoptosis of the cell depending on the nature of the signals (Wajant, 2002). Since immune cells possess various kinds of carbohydrate-binding receptors such as the lectin-like receptors (Kusumi et al., 2006; van Vliet et al., 2007) and the signals from the receptor bindings could modulate apoptosis of the cells (Sullivan et al., 2007; Fedele et al., 2007), some of the carbohydrate-containing molecules from plants would control survival of the cells (Srivastava and Kulshreshtha, 1989). A glycoside extract from oleander inhibited proliferation and induced apoptosis of prostate cancer cells (Winnicka et al., 2006) and an extract from Artemisia asiatica induced apoptotic death of the pancreatic inflammatory cells (Hahrm et al., 1998). A polysaccharide fraction from Artemisia iwayomogi suppressed apoptotic death of immune cells (Hwang et al., 2003) while a hot water polysaccharide 
extract from Anacyclus pyrethrum stimulated the proliferation of peritoneal cells (Bendjeddou et al., 2003).

Given that the binding of plant carbohydrates to the carbohydrate-binding receptors on immune cells could modulate function of the cells, effect of a carbohydrate fraction from Eclipta prostrata on the apoptosis of splenocytes has been studied. A mouse gene array has also been employed to determine the gene expression changes by the treatment of the fraction in order to have an idea on the nature of its anti-apoptotic activity.

\section{MATERIALS AND METHODS}

\section{Mice and Chemicals}

BALB/c mice were purchased from the Korea Experimental Animal Center (Seoul, Korea). Most of the cell culture reagents were obtained from the Sigma (St. Louis, MO, USA). Atlas Mouse cDNA Expression Array and Atlas Pure Total RNA Labeling System were purchased from Clonetech Lab (Palo Alto, CA, USA) and RNAgents Total RNA Isolation System was from Promega (Madison, WI, USA). TACS MTT Assay was purchased from R\&D systems (Minneapolis, MN, USA) and BD ApoAlert Annexin V-FITC kit and propidium iodide (PI) were from the BD Biosciences (Palo Alto, CA, USA). First-Strand cDNA Synthesis Kit was obtained from the Amersham Biosciences (Piscataway, NJ, USA) and Limulus Amebocyte Lysate was from the Cape Cod Inc. (East Falmouth, MA, USA).

\section{Purification of carbohydrate fractions from Eclipta prostrata}

An oriental herbal product of Eclipta prostrata was purchased from the Youngnam Oriental Drug Store (Gimhae, Korea) and a voucher specimen of the herb used in this study has been deposited at the Herbarium of the Bio-health Products Research Center, Inje University. A water-soluble crude extract was prepared by percolating the herb in high-pressure steam water for 3 hours and was then size-fractionated with distilled water using Sephadex G-50 column chromatography. The fractions containing carbohydrates were determined by the modified phenol sulfuric-acid method of total sugar determination (Taylor, 1995), producing three peaks around 32K, $6 \mathrm{~K}$ and $1 \mathrm{~K}$ dalton areas (Fig. 1). The fractions corresponding to each peak were pooled and named as the EPF0, EPF1 and EPF2 fractions, respectively. The fractions as well as the vehicle (distilled water) used in the following studies were all pre-tested for bacterial endotoxin by the gel clot assay using Limulus Amebocyte

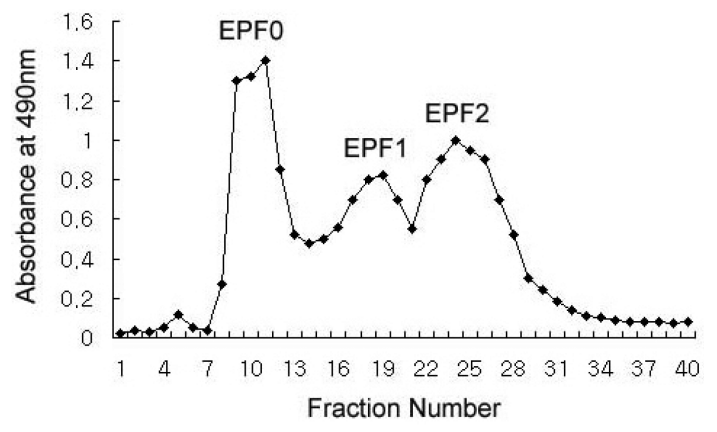

Fig. 1. Preparation of the carbohydrate fractions using Sephadex G50 column chromatography. A water-soluble crude extract from Eclipta prostrata was size fractionated using distilled water and the amounts of reducing sugar in the fractions were determined by the phenol sulfuric-acid method.

Lysate as described by the manufacturer (Cape Cod Inc.) in order to confirm their endotoxin-free states.

\section{Effects of the carbohydrate fractions on the survival of the mouse splenocytes in culture.}

Mouse splenocytes were collected from the corresponding tissue of 6 week-old female BALB/c mouse as described by Mishell and Shiigi (1980). Following the removal of red blood cells, the splenocytes were cultured in the DMEM $/ 10 \%$ FCS medium supplemented with the fractions at the final concentration of $1 \mathrm{mg} / \mathrm{ml}$. At the day 3,6 and 12 of the cultures, the numbers of live cells in the cultures were determined using Trypan Blue dye exclusion method. In order to examine the effect of the fractions on the apoptosis of the cells, a DNA fragmentation assay was also performed as described previously (Kroemer et al., 1997). Briefly, DNA samples containing small DNA fragments were prepared from each cell lysate following the treatment of the splenocytes for 4 hours with $1 \mathrm{mg} / \mathrm{ml}$ of each fraction, which were then subjected to a $1 \%$ agarose gel electrophoresis.

\section{Effect of the EPF2 fraction on the apoptosis of the mouse splenocytes in culture}

For the characterization of the anti-apoptotic activity of the EPF2 fraction, an MTT assay was employed to determine the viability of the cells as described by the manufacturer (TACS MTT reagent, R\&D systems). Following the incubation of mouse splenocytes in DMEM/ $10 \%$ FCS medium supplemented with $0.5 \mathrm{mg} / \mathrm{ml}, 1.0 \mathrm{mg} / \mathrm{ml}$ or $2.0 \mathrm{mg} / \mathrm{ml}$ of the EPF2 fraction for 4 hours, the cells were treated with the MTT Reagent until purple precipitates became evident. Each precipitate was dissolved in the Detergent Reagent and the absorbance at $595 \mathrm{~nm}$ was 
measured. The degree of the splenocyte apoptosis in the culture was also examined using a FACS analysis with annexin $\mathrm{V}$ and propodium iodide $(\mathrm{PI})$ as described by the manufacturer (BD Biosciences). Following the treatment of the cells with $1 \mathrm{mg} / \mathrm{ml}$ EPF2 fraction for 4 hours, the cells were stained with both annexin $\mathrm{V}$ and $\mathrm{PI}$ and examined by a Becton-Dickinson FACSCalibur single laser cytometer.

\section{Gene expression change in the EPF2-treated sple- nocytes}

Following the treatment of splenocytes with either the EPF-2 fraction or the vehicle, total RNAs were purified using the RNAgents Total RNA Isolation System as described by the manufacturer (Promega). The radioactive cDNA probes were then prepared from the RNAs using the Total RNA Labeling System as instructed by the manufacturer (Clonetech). The labeled cDNA probes were then hybridized with the Atlas Mouse cDNA Expression Arrays where the cDNA fragments from 588 different genes had been attached in duplicate on a positively charged nylon membrane. Following the hybridization, the membranes were exposed on x-ray films and analyzed using the Alpha Imager 1220 image analysis system (Alpha Innotech Cooperation, San Leandro, CA, USA) to determine the density of each hybridized spot. The expression level of each gene was compared following the normalization of each spot density using the signals from the positive and the negative control spots to minimize variations from blot to blot.

\section{RT-PCR analysis of MIP1- $\beta$ gene expression}

CDNAs were prepared using the First-Strand CDNA Synthesis Kit as the manufacturer's instruction (Amersham Biosciences) with the total RNA preparations from the EPF2- and the vehicle-treated cells. The cDNAs were then subjected to a PCR amplification reaction using the specific primer sets for $\beta$-actin and MIP1- $\beta$ genes. The amplification of $\beta$-actin gene was performed using a primer set of gcaccacaccttctacaatgag and aaatagcacagcctggatagcaac and that of MIP1- $\beta$ gene was done with a primer set of atgaagctctgcgtgtctgc and tcagttcaactccaagtcactcat. PCR reactions were performed under the following amplification conditions: a cycle of denaturing at $95^{\circ} \mathrm{C}$ for $5 \mathrm{~min}$, annealing at $55^{\circ} \mathrm{C}$ for $1 \mathrm{~min}$ and extending at $72^{\circ} \mathrm{C}$ for $1 \mathrm{~min}$, followed by 35 cycles of denaturing at $95^{\circ} \mathrm{C}$ for $1 \mathrm{~min}$, annealing at $53^{\circ} \mathrm{C}$ for $1 \mathrm{~min}$ and extending at $72^{\circ} \mathrm{C}$ for $1 \mathrm{~min}$. Following an additional extension at $72^{\circ} \mathrm{C}$ for $10 \mathrm{~min}$, the amplified DNA fragments were examined on a $1 \%$ agarose gel.

\section{Statistical analysis}

All experiments were performed in duplicate and repeated at least twice, and the results were statistically evaluated using Student's t-test. The P values less than 0.05 were regarded as significant.

\section{RESULTS AND DISCUSSION}

\section{Effect of the EPF2 fraction on splenocyte viability}

In order to examine the effect of the EPF0, EPF1 and EPF2 fractions on the survival of the mouse splenocytes in culture, the numbers of live cells in the cultures were counted following the Trypan Blue staining. While more than a half of the cells in the EFP2-treated culture were still alive, approximately $80 \%$ of cells in the EPFO- and the EFF1-treated cultures died out on the day 12 of the culture. At the time point, the vehicle-treated culture showed almost complete death of the cells (Fig. 2a), which is expected in a primary splenocyte culture. The survival rate of the cells in the EPF2-treated culture was more dramatic during the early phase of the culture period as the cells in the EPF2-treated culture did not show any sign of cell death until the day 6 of the culture while more than $40 \%$ of the cells were dead in the other cultures. Although the EPF2 treatment showed better survival of the splenocytes in the primary culture, it did not increase the number of live cells significantly during the culture period (Fig. 2a), suggesting that the EPF2 fraction might modulate the death of the cells. When the degrees of the apoptotic death of the cells were examined using a DNA fragmentation assay (Fig. 2b), its pat-
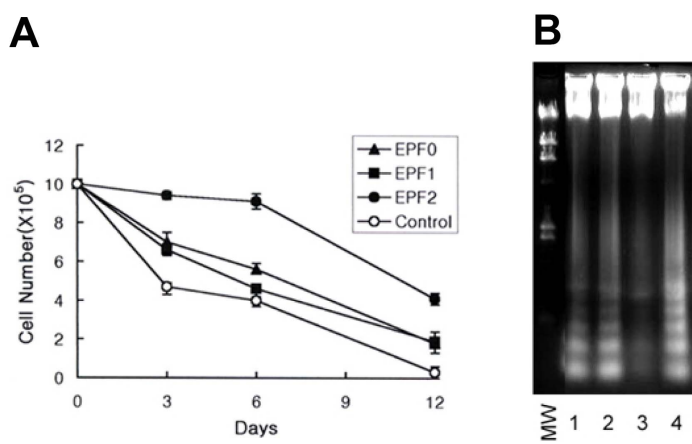

Fig. 2. Effects of the carbohydrarte fractions on the mouse splencytes in culture. The cells in the EPF2-treated cultures showed better survival as determined by the number of live cells in the cultures (a) and the degree of the DNA fragmentation of the cells (b). The lanes from 1 to 4 in the panel b) represent the cells treated with the EPF0, EPF1, EPF2 and vehicle, respectively. MW represents the DNA fragments from HindllIdigested $\lambda$ DNA. 
tern appeared very similar to that of the live cell counting study (Fig. 2a). While the cells in the vehicle-, the EPF0and the EPF1-treated cultures produced significant amount of the small DNA fragments, the EPF2-treated cells showed very low level of DNA fragmentation (Fig. $2 b$ ), which indicated that the EPF2 fraction suppressed apoptosis of splenocytes and thus extended survival of the cells. In order to have an idea on the sugar-containing molecules involved in the anti-apoptotic activity, the carbohydrate compounds in the EPF2 fraction were examined using the Agilent ZORBAX High Performance Size Exclusion Chromatography (Agilent Technologies, Santa Clara, CA, USA) with PSM 60S column. As seen in Fig. 3, most of the carbohydrate-containing compounds in the fraction appeared to be around the size of sucrose molecule, suggesting that one or more hydrophilic sugar-containing compounds such as oligosaccharides or glycoside compounds could present the antiapoptotic activity of the fraction.

The degrees of the cellular death in the EPF2-treated culture were determined quantitatively using an MTT reduction assay and a FACS analysis. The EPF2 supplementation showed significant increase in the MTT reduction in a dose-dependent fashion (Fig. 4a), indicating that the fraction could be responsible for the survival of the splenocytes. The FACS analysis using annexin V and PI also supports anti-apoptotic activity of the fraction. Although there was not much difference in the mean annexin V fluorescence intensity in the annexin V-positive cells between the EPF2- and the vehicle-treated cultures (Fig. 4b, left), the average number of cells

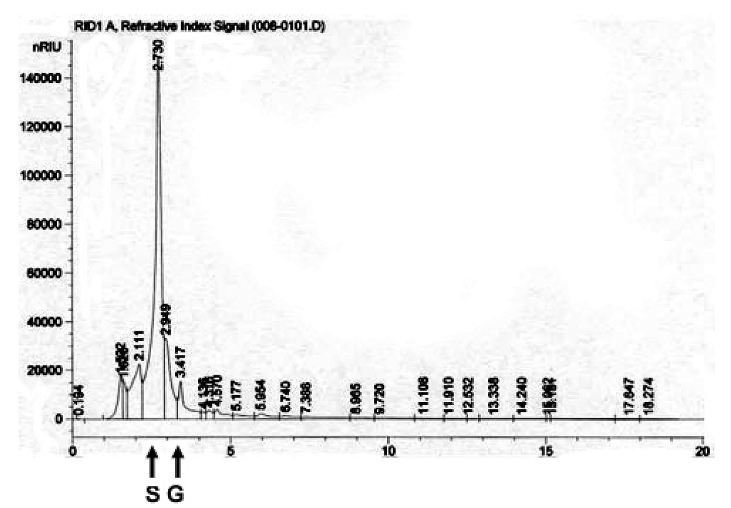

Fig. 3. Characterization of the carbohydrate compounds in the EPF2 fraction using PSM Size exclusion chromatography. The EPF2 fraction was size fractionated using distilled water and the carbohydrates were examined by an RI detector. The arrows marked by " $S$ " and "G" represent the peak areas for sucrose and glucose, respectively, used as the molecular weight standards. expressing annexin $\mathrm{V}$ was much lower in the EPF2treated culture than in the vehicle-treated culture (Fig. 4b, right). Since annexin $\mathrm{V}$ specifically binds to phosphatidylserine exposed on the cells under apoptosis (Winnicka et al., 2007), this result indicated that the EPF2 fraction suppressed the apopototic death of the splenocytes. The two-color FACS study using annexin V and PI showed that the EPF2 fraction significantly reduced the cell population stained by both annexin $\mathrm{V}$ and $\mathrm{PI}$ (upper right corner, Fig. 4c), indicating that the fraction mainly reduced the number of splenocytes in the late apoptotic stage probably by delaying apoptosis progression in the cells. Considering that the major populations in spleen are lymphocytes and antigen-presenting cells important in the immune response, the EPF2 fraction might exert its anti-apoptotic activity on those cells and thus modulate immune response in spleen. Provided that the anti-apoptotic effect on splenocytes by the EPF2 fraction could be presented in vivo, the fraction would affect the maintenance or activation of the immune cells including $T$ cells and thus could be applied to the control of the diseases
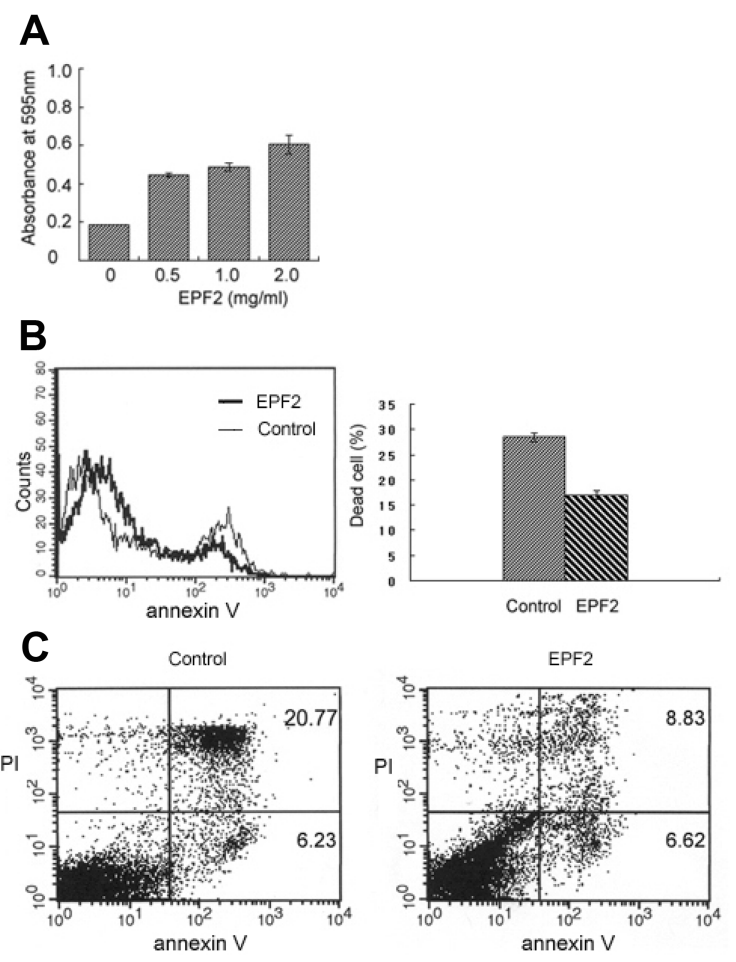

Fig. 4. Effect of the EPF2 fraction on the apoptotic death of the splenocytes in culture. The panel a) represents the MTT reduction assay and the panel $b$ ) shows a FACS result of annexin $\mathrm{V}$ staining (left) with the average number of annexin $\mathrm{V}$-positive cells (right). The panel c) is a two color FACS analysis with annexin $\mathrm{V}$ and $\mathrm{PI}$. 
A

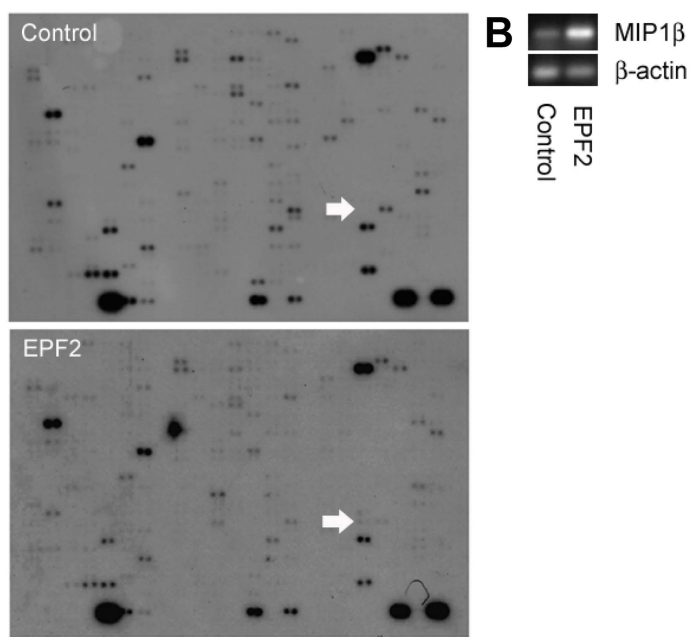

Fig. 5. Result of the gene arrays hybridized with the cDNAs from the EPF2- and the vehicle-treated cells (a) and the RTPCR analysis for the MIP1- $\beta$ gene expression (b). Spots representing the MIP1- $\beta$ gene were indicated by the arrows in the panel a).

resulted from the immune cell apoptosis such as AIDS where the death of both HIV-infected and -uninfected CD4 T cells is important in the development of the symptom (Alimonti et al., 2003). In this regard, it is interesting that Eclipta prostrata has already been prescribed for AIDS patients in Thailand (Tewtrakul et al., 2007).

\section{Gene expression change by the EPF2 treatment}

To obtain preliminary information on the mechanism of the anti-apoptotic activity of the EPF2 fraction, a gene array technology was employed to screen the genes whose expressions were changed by the EPF2 treatment (Fig. 5a). A mouse gene array containing a panel of 588 cDNAs involved in the signal transduction and apoptosis was probed with the cDNAs either from the EPF2or the vehicle-treated splenocytes. Among the numerous genes whose expressions were changed by the EPF2 treatment, at least 2-fold up-regulation was observed in 3 genes while more than 2-fold down-regulation in 12 genes (Table 1), which includes a number of cytokine and cytokine receptor genes. The up-regulations of the cytokine receptor common gamma subunit $(\gamma-C)$ and the macrophage inflammatory protein 1 beta (MIP1- $\beta$ ) could explain the anti-apoptotic activity of the EPF2 fraction since MIP1- $\beta$ is shown to be up-regulated upon stimulation in monocytes and lymphocytes (Modi et al., 2001) and $\gamma-C$ is known to be important for $T$ and $B$ cell activation (Akbar et al., 1996). Among the genes whose expressions were reduced by the EPF-2 treatment, the down-regulations of TANK, STAT1, TGF- $\beta 1$ and CDKN1B could explain the anti-apoptotic activity of the fraction. Both TANK and STAT1 genes are important in the apoptosis progression in the TNF receptor pathway. TANK gene is known to induce apoptosis by an adaptor protein

Table I. Genes down- or up-regulated by the EPF2 treatment.

\begin{tabular}{cc}
\hline Genes & Fold of expression \\
\hline macrophage inflammatory protein 1 beta (MIP1- $\beta$; MIP1B) & +3 \\
cytokine receptor common gamma subunit $(\gamma-\mathrm{C})$ & +2 \\
glucose-6-phosphate isomerase (GPI) & +2 \\
signal transducer \& activator of transcription 1 (STAT1) & -4 \\
vimentin (VIM) & -4 \\
transforming growth factor beta 1 (TGF- $\beta 1$; TGFB1) & -4 \\
split hand/foot deleted gene 1 (SHFDG1) & -3 \\
integrin beta 2 (ITGB2) & -3 \\
TRAF family member-associated NF-kappaB activator(TANK) & -3 \\
special AT-rich sequence-binding protein 1 (SATB1) & -3 \\
proviral integration site 1 proto-oncogene (PIM1) & -3 \\
dipeptidyl peptidase IV (DPPIVB; DPP4) & -2 \\
nucleoside diphosphate kinase B (NDP kinase B; NDKB) & -2 \\
glutathione reductase 1 (GR1) & -2
\end{tabular}


related with TNF receptor (Annumziata et al. 2000) and STAT1 is also required for the expression of the apoptosis enzymes including caspases (Kumar et al., 1997). The down-regulation of TGF- $\beta 1$ and CDKN1B could result in the suppression of the splenocyte apoptosis since TGF- $\beta$ could lead cell death through the activation of Cdc2 and Cdk2 (Choi et al., 1999) and CDKN1B might mediate TGF- $\beta$-induced G1 arrest (Katayose et al., 1997). Although more studies are required for the mechanism of the anti-apoptotic activity of the EPF2 fraction, these results suggest that the fraction may modulate splenocyte apoptosis through the regulation of the cytokine/cytokine receptor pathway of the cells.

The up-regulation of the MIP1- $\beta$ gene expression by the EPF2 treatment needs mentioned further with regard to HIV infection and AIDS development. MIP1- $\beta$ belongs to the CC chemokine subfamily directing the migration of specific subsets of leukocytes (Modi et al., 2001) and was also identified as a potent HIV-blocking factor produced by CD8 T cells (Kamin-Lewis et al., 2001). Since HIV infection to CD4 $\mathrm{T}$ cells requires $\mathrm{CC}$ chemokine receptor as a co-receptor and the occupation of the receptor by the CC chemokines such as MIP-1 $\beta$ profoundly inhibits HIV infection (Amara et al., 1997), the up-regulation of MIP1- $\beta$ by the EPF2 fraction might prevent or inhibit a new HIV infection of CD4 T cells. As seen in Fig. 5a, the MIP1- $\beta$ spots of the EPF2-treated array appeared as the faint dots while those of the control array were too light to be located, indicating that the MIP1- $\beta$ expression could be increased by the EPF2 treatment. Through the normalization using the spot densities of the positive control genes in the bottom row of the vehicle- or the EPF2treated array, the MIP1- $\beta$ expression level of the EPF2treated cells was measured to be 3 times higher than that of the vehicle-treated cells (Table 1). RT-PCR analysis also showed the MIP1- $\beta$ expression was markedly increased by the EPF2 treatment (Fig. 5b), indicating that the expression of the CC chemokine can be up-regulated by the fraction. In addition to the possible contribution of the anti-apoptotic activity of the EPF2 fraction to the survival of CD4 T cells, this prospective blockingactivity of HIV entry by the increased MIP1- $\beta$ makes Eclipta prostrata a strong candidate for the development of an anti-AIDS drug from a natural source. Interestingly, Eclipta prostrata already has been prescribed for the treatment of HIV infection among Thai doctors and a coumarin derivative from the plant showed inhibitory activity against HIV-1 protease and integrase (Tewtrakul et al., 2007).

In this study, we have shown that the suppression of the apoptotic death of splenocytes in culture by the treatment of a water-soluble carbohydrate fraction purified from Eclipta prostrata. We have also presented changes of gene expression pattern by the treatment of the fraction, which includes the increased transcription of MIP1- $\beta$ gene. This study would help to identify a prospective natural compound from Eclipta prostrata for treatment or prevention of the diseases where cytokine regulation and apoptosis play important roles.

\section{ACKNOWLEDGEMENT}

This work was supported by the 2003 Inje University Research Grant.

\section{REFERENCES}

Akbar, A. N., Borthwick, N. J., Wickremasinghe, R. G., Panayoitidis, P., Pilling, D., Bofill, M., Krajewski, S., Reed, J. C. and Salmon, M. (1996). Interleukin-2 receptor common gammachain signaling cytokines regulate activated $\mathrm{T}$ cell apoptosis in response to growth factor withdrawal: selective induction of anti-apoptotic (bcl-2, bcl-xL) but not pro-apoptotic (bax, bclxS) gene expression. Eur. J. Immunol. 26, 294-299.

Alimonti, J. B., Ball, T. B. and Fowke, K. R. (2003). Mechanisms of CD4+ T lymphocyte cell death in human immunodeficiency virus infection and AIDS. J. Gen. Virology, 84, 16491661.

Amara, A., Le Gall, S., Schwartz, O., Salamero, J., Montes, M., Loetscher, P., Baggiolini, M., Virelizier, J.-L. and ArenzanaSeisdedos, F. (1997). HIV Coreceptor downregulation as antiviral principle: SDF-1-dependent internalization of the chemokine receptor CXCR4 contributes to inhibition of HIV replication. J. Exp. Med. 186, 139-146.

Annumziata, C. M., Safiran, Y. J, Irving, S. G., Kasid, U. N. and Cossman, J. (2000). Hodgkin diseases: pharmacologic intervention of CD40-NF kappa B pathway by a protease inhibitor. Blood 96, 2841-2848.

Choi, K. S., Eom, Y. W., Kang, Y., Ha, M. J., Rhee, H., Yoon, J. W. and Kim, S. J. (1999). Cdc2 and Cdk2 kinase activated by transforming growth factor-beta1 trigger apoptosis through the phosphorylation of retinoblastoma protein in $\mathrm{FaO}$ hepatoma cells. J. Biol Chem. 274, 31775-31783.

Bendjeddou, D., Lalaoui, K. and Stta, D. (2003). Immunostimulating activity of the hot water-soluble polysaccharide extracts of Anacycyclus pyrethrum, Alpinia galanga and Citrullus colocynthis. J. Ethnopharmacol. 88, 155-160.

Fedele, G. Celestino, I., Spensieri, F., Frasca, L., Nasso, M., Watanabe, M., Remoli, M. E., Coccia, E. M., Altieri, F. and Ausiello, C. M. (2007). Lipooligosaccharide from Bordetella pertussis induces mature human monocyte-derived dendritic cells and drives a Th2 biased response. Microbes Infect. 9, 855-863.

Hahm, K. B., Kim, J. H., You, B. M., Kim, Y. S., Cho, S. W., Yim, H., Ahn, B. O. and Kim, W. B. (1998). Induction of apoptosis with an extract of Artemisia asiatica attenuates the severity of 
cerulein-induced pancreatitis in rats. Pancreas 17, 153-157.

Han. Y., Xia, C., Cheng, X., Xiang, R., Liu, H., Yan, Q. and Xu, D. (1998). Preliminary studies on chemical constituents and pharmacological action of Eclipta prostrata L. Materia Medica. 23, 680-682.

Ishizaki, Y., Cheng, L., Mudge, A. W. and Raff, M. C. (1995). Programmed cell death by default in embryonic cells, fibroblasts, and cancer cells. Mol. Biol. Cell. 6, 1443-1458.

Hwang J., Chung, H., Bae, E., Lee, A., Ji H., Park, D., Jung, H. J., Cho, C. W, Choi, H., Lee, D., Lee, K. and Youn, H. (2003). The Polysaccharide Fraction AIP1 from Artemisia iwayomogi Suppresses Apoptotic Death of the Mouse Spleen Cell in Culture. Arch. Parm. Res. 4, 294-300.

Kamin-Lewis, R., Abdelwahab, S. F., Trang, C., Baker, A., DeVico, A. L., Gallo, R. C. and Lewis, G. K. (2001). Perforinlow memory CD8+ cells are the predominant $T$ cells in normal humans that synthesize the beta -chemokine macrophage inflammatory protein-1beta. Proc. Natl. Acad. Sci. USA 98, 9283-9288.

Katayose, Y., Kim, M., Rakkar, A. N., Li, Z., Cowan, K. H. and Seth, P. (1997). Promoting apoptosis: a novel activity associated with the cyclin-dependent kinase inhibitor p27. Cancer Res. 57, 5441-5445.

Kobari, M., Yang, Z., Gong, D., Heissmeyer, V., Zhu, H., Jung, Y. K., Angelica, M., Gakidis, M., Rao, A., Sekine, T., Ikegami, F., Yuan, C. and Yuan, J. (2004). Wedelolactone suppress LPS- induced caspase-11 expression by directly inhibiting the IKK complex. J. Cell. Death Differ. 11, 123-130.

Kroemer, G., Bosca, L., Zamzami, N., Merchetti, P., Hortelano, S. and Martinez-A, C. (1997). Detection of apoptosis and apoptosis-associated alterations. In: Lefkovits I. Immunology Methods Manual, Academic Press, San Diego, pp. 11111121.

Kumar, A., Commane, M., Flickinger, T. W., Horvath, C. M. and Stark, G. R. (1997). Defective TNF-alpha-induced apoptosis in STAT1-null cells due to low constitutive levels of caspases. Science 278, 1630-1632.

Kumari, C. S., Govindasamy, S. and Sukumar, E. (2006). Lipid lowering activity of Eclipta prostrata in experimental hyperlipidemia. J. Ethnopharmacol. 24, 332-335.

Kusumi, M., Yamashita, T., Fujii, T., Nagamatsu, T., Kozuma, S. and Taketani, Y. (2006). Expression patterns of lectin-like natural killer receptors, inhibitory CD94/NKG2A, and activating CD94/NKG2C on decidual CD56bright natural killer cells differ from those on peripheral CD56dim natural killer cells. J. Reprod. Immunol. 70, 33-42.
Lindsten, T., Ross, A. J., King, A., Zong, W., Rathmell, J. C., Shiels, H. A., Ulrich, E., Waymire, k. G., Mahar, P., Frauwirth, K., Chen, Y., Wei, M., Eng, V. M., Adelman, D. M., Simon, M. C., Ma, A., Golden, J. A., Evan, G., Korsmeyer, S. J., MacGregor G. R. and Thompson, C. B. (2000). The combined functions of proapoptotic Bcl-2 family members Bak and Bax are essential for normal development of multiple tissues. Molecular Cell 6, 1389-1399.

Luo, X., Budihardjo, I., Zou, H., Slaughter, C. and Wang, X. (1998). Bid, a Bcl2 interacting protein, mediates cytochrome c release from mitochondria in response to activation of cell surface death receptors. Cell 94, 481-490.

Modi, W. S., Bergeron, J. and Sanford, M. (2001). The human MIP-1-beta chemokine is encoded by two paralogous genes, ACT-2 and LAG-1. Immunogenetics 53, 543-549.

Mores, W. B., do Nascimento, M. C., Parente, J. P., da Silvia, M. H., Melo, P. A. and Suarez-Kurtz, G. (1998). Neutralization of lethal and myotoxic activitis of South American rattle snake venom by extracts and constituents of the plant Eclipta prostrata (Asteraceae). Toxicon 27, 1003-1009.

Srivastava, R. and Kulshreshtha, K. (1989). Bioactive polysaccharides from plants. Phytochemistry 28, 2877-2883.

Sullivan, B. A. and Kronenberg, M. (2007). TCR-mediated recognition of glycolipid CD1 complexes. Curr. Top Microbiol. Immunol. 314, 165-193.

Taylor, K. (1995). A modification of the phenol sulfuric acid method of total sugar determination. Appl. Biochem. Biotechnol. 53, 207-214.

Tewtrakul, S., Subhadhirasakul, S., Cheenpracha, S. and Karalai, C. (2007). HIV-1 protease and HIV-1 integrase inhibitory substances from Eclipta prostrata. Phytother. Res. 21, 1092-1095.

Van Vliet, S., Dunnen, J., Gringhuis, S., Geijtenbeek, T. and van Kooyk, Y. (2007) Innate signaling and regulation of dendritic cell immunity. Curr. Opin. Immunol. 19, 435-440.

Wajant, H. (2002) The Fas signaling pathway: more than a paradigm. Science 296, 1635-1636.

Winnicka, K., Bielawski, K. and Bielawska, A. (2006) Cardiac glycosides in cancer research and cancer therapy. Acta. Polon Pharm. 2, 109-115.

Winnicka, K., Bielawski, K., Bielawska, A. and Miltyk, W. (2007) Apoptosis-Mediated Cytotoxicity of Ouabain, Digoxin and Proscillaridin A in the Estrogen Independent MDA-MB-231 Breast Cancer Cells. Arch. Pharm. Res. 30, 1216-1224. 